\title{
Adaptive Design for Educational Hypermedia Environments and Bio-Educational Adaptive Design for 3D Virtual Learning Environments
}

\author{
Flavia Santoianni ${ }^{\mathrm{a}}$, Alessandro Ciasullo ${ }^{\mathrm{b}}$ \\ ${ }^{a}$ University of Naples Federico II, Italy, bes@unina.it, ORCID 0000-0003-3382-5765 \\ ${ }^{b}$ University of Naples Federico II, Italy, alessandro.ciasullo@unina.it
}

\begin{abstract}
Adaptive learning environments design has been originally influenced by the adaptive learning environments model, which has been recently re-shaped by the bio-educational adaptive approach. Adaptive and bio-educational models share the common main idea that education should be adaptive. Since the 90's the adoption of an adaptive educational point of view have been at the base of adaptive educational hypermedia systems, which design joins interest towards learners' individual differences with adaptive learning environments research. Educational hypermedia systems have been overcome by the technology of $3 D$ Virtual Learning Environments. Some emerging questions are related to the design criteria of adaptive learning environments. Which lessons learned from adaptive hypermedia systems design could be now applied to VLEs' design? How a virtual learning environment should be designed to be adaptive? This research tries to answer to these questions by describing Federico 3DSU, an educational University 3D Virtual Learning Environment which has been designed with adaptive criteria, according to bio-educational model
\end{abstract}

Keywords: educational design, learning environments

To be motivated to master concepts and skills, students need to see the connection of what they are learning to the rest of their lives and to the mental models they already use.

Dede

To ignore learners' preferences may perhaps lead to sub-optimal levels of motivation, engagement in the learning process and, ultimately, learning performance.

Sadler-Smith, Smith

\section{Adaptive Educational Environments and Bio-Educational Adaptive Design}

Over the last fifteen years, the field of education has developed an increased interest towards integrationist approaches to the study of mind development and education (Frauenfelder, Santoianni, 2003; Fischer, Daniel, Immordino-Yang, Stern, Battro, Koizumi 2007; Fischer, Goswami, Geake, 2010; Schwartz, 2015; Santoianni, 2018).

Biological, educational, and psychological aspects of individuals' behaviors have been constantly intertwined, while interpreting the cognitive development of knowledge structures (Santoianni, 2016c) and their modifiability according to educational change (Santoianni, 2006). The "cognitive prism" has been considered as a holistic and synergic hub, in which processual, emotional, and perceptual dimensions are merged at different organizational levels, while individual idiosyncrasy is embedded in the evolution of sociocultural interactions (Santoianni, 2007).

Educational design has been consequently re-shaped on the base of the multiple contextual relations and co-actions which may influence the adaptive mutual dynamics between organisms and environments, which are interactively related to the continuous ontogenetic process of individuals' differentiation (Santoianni, 2004). During learning history lifetime, each individual develops her/his experience through environmental adaptation, which should be encouraged by 


\section{Adaptive Design for Educational Hypermedia Environments and Bio-Educational Adaptive Design for 3D Virtual Learning Environments \\ Santoianni, Ciasullo}

educational support in designed explicit and/or implicit learning environments to sustain the personal adaptive learning potential to cope with the contextual complexity.

In bio-educational framework, experimental models of education are characterized by situated, dynamic, and continuously evolving functions, designed to cope with the unpredictability of knowledge processes, which may be considered heterogeneous, discontinuous, and dynamic (Santoianni, 2017). Educational support is intended then as a ubiquitous endeavor to enhance individual adaptive learning competencies through adaptive learning environments design.

Adaptive learning environments design has been originally influenced by the adaptive learning environments model (ALEM) (Wang, 1984), which has been recently re-shaped by the bio-educational adaptive approach (Frauenfelder, Santoianni, Ciasullo, 2018). Adaptive and bio-educational models share the common main idea that education should be adaptive: i.e., education is a dynamic and specific process, which needs to be tailored according to the different ways in which learners evolve and to their own personal history of learning.

As a consequence, bio-educational adaptive design focuses on situated and embodied approaches, which customize the educational offer of learning content and materials in relation to the mutual interaction between explicit and implicit, unaware, nonverbal, and prototypal processing (Santoianni, 2011); to the structural modularity of learning development, intertwined between the cognitive, emotional, and perceptual bodily-organismic entanglement (Santoianni, 2007; Ciasullo, 2015); and to the synergies of the continuously active dynamics between the individual/collective relationship (Santoianni, 2006), which influences evolutionary compatibility between learners and concurs to understand educability criteria and boundaries.

Since the 80's the aim of the adaptive learning environments model (Wang, 1984) was to innovate educational programs by facilitating learning in order to meet the individual learning needs of students of different cognitive, cultural, and socioeconomic backgrounds. Learners may indeed achieve, within ALEM educational program, just basic academic skills, self-efficacy, and personal cognitive responsibility to become integrated members of the learning community. At the same time, also bio-educational adaptive design focuses on core knowledge and basic skills acquisition, but it stresses more in particular on designing educational methodologies aiming to foster learners' cognitive identity awareness through personalized approaches (Santoianni, 2011, 2014; Santoianni, Osorio Guzmàn, 2015).

Since the 90's the adoption of an adaptive educational point of view have been at the base of adaptive educational hypermedia systems, which design joins interest towards learners' individual differences with adaptive learning environments research. Nowadays, adaptive education focuses on virtual learning environments. This paper discusses the core idea of adaptation in the field of education in the two following parts, respectively showing how adaptive design may influence both educational hypermedia and 3D virtual learning environments, in order to gain high quality criteria to develop adaptive educational environments.

The main idea at the root of adaptive systems design in educational hypermedia environments is to empower a more flexible student-centered approach through learning environments, which can be modified according to individual differences, preferences, skills, and needs. Hypermedia adaptation is then focused on learning styles - cognition and learning centered, thinking styles - approaches. But, since hypermedia systems have been recently overcome by 3D, the educational question shifts towards which adaptive aspects of hypermedia may be applied again to virtual learning environments and how to design a virtual learning environment to let it be adaptive.

Features as the user friendliness, everyday setting illusion, intuitive facilitations, intensive interaction, and feedback attention are taken into consideration to gain effective virtual learning environments. Every learning environment should be anyway designed according to the cognitive, emotional, and perceptual-bodily-organismic dimension of learning, which is at the root of any educability criteria tailored to adaptively customize educational offer according to learning needs.

\section{Adaptive Systems for Educational Hypermedia Environments Design}

Adaptive educational hypermedia systems develop design of adaptation based on learning styles information (Papanikolaou, Grigoriadou, 2004) and may be considered alternative to the traditional "one-size-fits-all" approach because adaptive hypermedia focus on the preferences of each individual user and adapt themselves to her/his needs (Brusilovsky, 2003).

Adaptive hypermedia support web-based instruction for learners with very different backgrounds of age, gender, domain, experiences of learning (Sadler-Smith, Smith, 2004) and consequently specific individual preferences, skills, and needs. The core question concerns then how web-based instruction may be used by learners with idiosyncratic characteristics, if all users feel always able to personally select meaningful choices without disorientation problems, and which kinds of individual differences may eventually lead to different patterns of interaction (Chen, Paul, 2003).

Since pioneeristic adaptive educational hypermedia systems developed in the earliest 90's, their starting point was the categorization of different styles, preferences and strategies (Sadler-Smith, Smith, 2004) which can guide the selection of the appropriate adaptation technologies (Papanikolaou, Grigoriadou, 2004). The conceptual systematization 


\section{Adaptive Design for Educational Hypermedia Environments and Bio-Educational Adaptive Design for 3D Virtual Learning Environments \\ Santoianni, Ciasullo}

of styles implies the possibility of defining them as a theoretical construct (Sternberg, Zhang, 2001) - and this issue may anyway be controversial (Santoianni, 2014).

Styles have been originally defined as adaptive mechanisms of control which mediate between individual needs and environment's demands (Wallach, Kogan, 1965) and are still considered the preferential ways in which individuals process information and cope with cognitive tasks (Zhang, Sternberg, 2006). Their field of research includes cognitive, learning, and thinking styles.

Cognition centred approaches (Sternberg, Grigorenko, 1997) are related to perceptual functioning, impulsivity versus reflectivity, intuition versus analysis, holist versus serialist, convergent versus divergent, assimilation versus exploration, concrete versus abstract thinking, verbalizer versus visualiser model, and more.

Learning centred approaches (Kolb, 1978) concern the ways in which individuals prefer to learn (Dunn, Dunn, 1978) and are related to teaching styles (Fischer, Fischer, 1979). Kolb (1984) suggests a four-stage model including associations between concrete experience and abstract conceptualisation, reflective observation and active experimentation. Within Kolb's model, learning styles are subdivided in four types (assimilator, accommodator, diverger, and converger). In Honey and Mumford (1986) model, reciprocal links are shown between the learning process (the learning cycle) and the learning styles (activist, reflector, theorist and pragmatist).

Thinking styles (Sternberg, 1998) are finally the preferred ways to use individual skills and have been categorized in creative, normative, and relative (Zhang, Sternberg, 2005).

Compared to strategies, which have an adaptive nature in themselves, styles are seen as more stable (Sternberg, Grigorenko, 2001) but not invariable (Sadler-Smith, Smith, 2004) because they may be influenced by learning context's demands (Sternberg, 1997). The dynamic interaction between the system, the domain, and the learner model may influence systems to use learning styles information to design instruction, according content type/sequencing on research about different styles' preferred ways of learning or adapting to learners' cognitive activity instructional strategies which concern global or analytical approaches, program or learner control options, advance or post organizers, minimum or maximum of instructions, content structure, and related users' feedback.

There are two main classes of hypermedia adaptation: adaptive presentation and adaptive navigation support.

To improve content understanding, adaptive presentation technologies play a role at content level by tailoring and customizing learning content according to learners' styles and providing multiple types of materials and resources, which can be re-ordered on the base of learners' preferences (Papanikolaou, Grigoriadou, 2004). Adaptive presentation aim is to personalize content to match with students' characteristics in two different ways: adaptive text - that is, different users may get different texts in the same page context - and adaptive layout, which doesn't change the text but the layout of the page (Chen, Paul, 2003).

Adaptive navigation support is instead based on adaptation at structural level and it is designed to enhance learners' orientation and to meet navigation needs and habits through the change of visible links appearance. Through a browsing-based access to information, the system prioritizes the most relevant items and guides learners according to their interests, thus increasing users' speed of navigation.

Adaptive hypermedia systems support users' navigation by implicitly limiting the browsing space, suggesting the relevant links to follow and adding related comments to visible links to avoid the phenomenon of feeling "lost in hyperspace" (Brusilovsky, 2003).

Common technologies to adapt the links are direct guidance, sorting, hiding, annotation, and generation, which allow more goal-oriented learning and navigation (Brusilovsky, 2001).

Adaptive hypermedia systems re-shape educational content in relation to the user's knowledge. A key issue is indeed the level of user's prior knowledge of the subject (Chen, Paul, 2003). Restrictive technologies as direct guidance or hiding seems to be more suitable for users who are unfamiliar with the educational content, while enriched technologies as annotation and multiple link generation seems to be more applicable for users who are already acquainted with the educational content.

This leads to the consideration that adaptation technology should be developed according to users' different levels of knowledge in order to select the more appropriate technologies and that, consequently, adaptive hypermedia should become meta-adaptive hypermedia systems - that is, systems which have at disposal several different adaptation technologies, are aware of the boundaries of application of each technology, and are designed to adaptively select the technologies which best fits with specific users and monitored contexts (Brusilovsky, 2003).

Adaptive collaboration support means instead to use system's knowledge about learners' characteristics to influence social interaction by matching groups for collaborative learning. It supports adaptive learning through social interaction, communication, and collaboration (Paramythis, Loidl-Reisinger, 2004).

The research field of individual differences and preferences in styles is linked to flexible learning research, focusing in particular on the concepts of self-direction, learning styles and instructional preferences, modes of information presentation and structure of learning programs (Sadler-Smith, Smith, 2004). Self-directedness is a key word for learning environments design, since it is linked to the idea of learner's autonomy - collaboration is not always perceived as needed - and to personalized instruction. Instructional design is indeed both related to learners and environments. 


\section{Adaptive Design for Educational Hypermedia Environments and Bio-Educational Adaptive Design for 3D Virtual Learning Environments \\ Santoianni, Ciasullo}

In adaptable systems (Wolf, 2002) the locus of control can both lie with the system, which manage learners' data in a system-controlled way, or with the learner, if the system supports end-user modifiability (Santoianni, Ciasullo, De Paolis, Nunziante, Romano, 2018). Adaptive control may be then given in a balancement between adaptivity and adaptability (Magoulas, Papanikolaou, Grigoriadou, 2003). Individual users' models are related to users' learning history (Santoianni, 2000, 2006) and may be intertwined with collaborative models emerging in similar groups of learners (Paramythis, Loidl-Reisinger, 2004). Through instructional design, learners may gradually become aware of her/his preferred style by exploring environmental available opportunities to learn by using different styles, and may enhance their own cognitive flexibility (Barak, Levenberg, 2016).

In adaptive hypermedia systems, tutor-centered style of traditional intelligent tutoring systems is then re-shaped with a more flexible student-centered approach where learning environments are modified according to individual differences to facilitate learners' approach to educational materials (Wolf, 2002). On the other hand, modelling adaptive systems' behaviour depends both on adaptation logics, based on logic-based reasoning engines which assess required adaptations, and on adaptation actions, which provide the system with the needed actions for adaptation (Paramythis, Loidl-Reisinger, 2004)

To encourage cognitive flexibility, technological learning environments should define typographical features of textual devices in relation to graphical/pictorial images and should tailor hypertext and links. Moreover, they should foresee a flexible delivery of learning, which may allow learners to follow personal routes starting from given learning programs.

Print-based and computer-based instructional materials as well as audio/video instructional materials and collaborative learning methods should be provided to accommodate instructional preferences. Learning materials should be presented or converted in more than one information processing format and advance organizers as maps may contribute to differently connect concepts, through tree-type (Novak, Gowin, 1984; Novak, 1998) and web-type (Buzan, Buzan, 2000) structures.

\section{Bio-Educational Adaptive Design for 3D Virtual University Digital Education}

Educational hypermedia systems have been overcome by the technology of 3D Virtual Learning Environments. Some emerging questions are related to the design criteria of adaptive learning environments. Which lessons learned from adaptive hypermedia systems design could be now applied to VLEs' design? How a virtual learning environment should be designed to be adaptive? This research tries to answer to these questions by describing Federico 3DSU, an educational University 3D Virtual Learning Environment which has been designed with adaptive criteria, according to bio-educational model (Frauenfelder, Santoianni, 2003; Santoianni, Ciasullo, 2017; Frauenfelder, Santoianni, Ciasullo, 2018).

Federico 3DSU is one of the first Italian prototypes of a 3D University Virtual Learning Environment (Santoianni, Ciasullo, De Paolis, Nunziante, Romano, 2018), which aims to improve the quality of Italian University education by linking in particular the University of Naples Federico II to the 3D international network of Universities, not yet enough developed in Italy. Federico 3DSU reproduces the Department of Humanities of the University of Naples Federico II in its squared shape with a central courtyard and four complexes in its corners (A, B, C, D). This educational University environment has been designed to motivate the future University choice of high school students and not yet enrolled students, and to give already enrolled attending and non-attending students to University of Naples Federico II the opportunity of fruition of digital resources to sustain and empower ongoing learning processes. The use of adaptive criteria is then highly significative to facilitate the narrowing of students to the University experience.

To be adaptive, a 3D Virtual Learning Environment should be easy to use, i.e. user friendly. The user has to have the possibility to easily navigate inside it. Since the spatial structure of a learning environment may influence students' performance (Belingard, Péruch, 2000), Federico 3DSU has been designed as a space of exploration structured following the easy architecture of the inference logic model of the Elementary Logic theory (Fig. 1). 


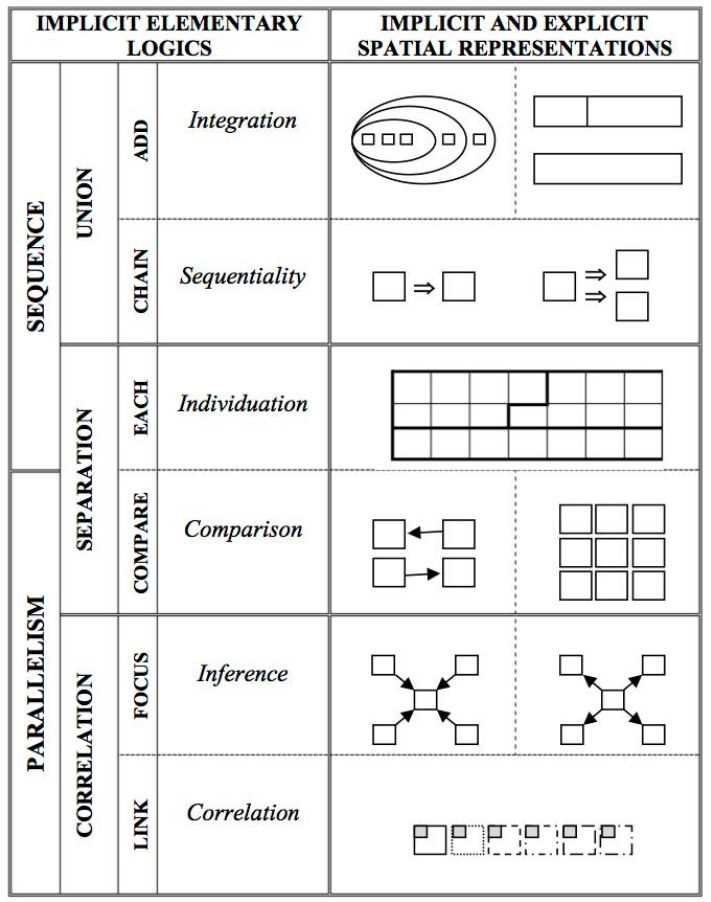

Fig. 1

According to the Elementary Logic theory (Santoianni, 2011, 2014), the spatial structure of a learning environment is influenced by explicit/implicit logic models, which act as learning patterns of connection between explicit and implicit, spatially represented as the inference logic model (focus Fig. 2)

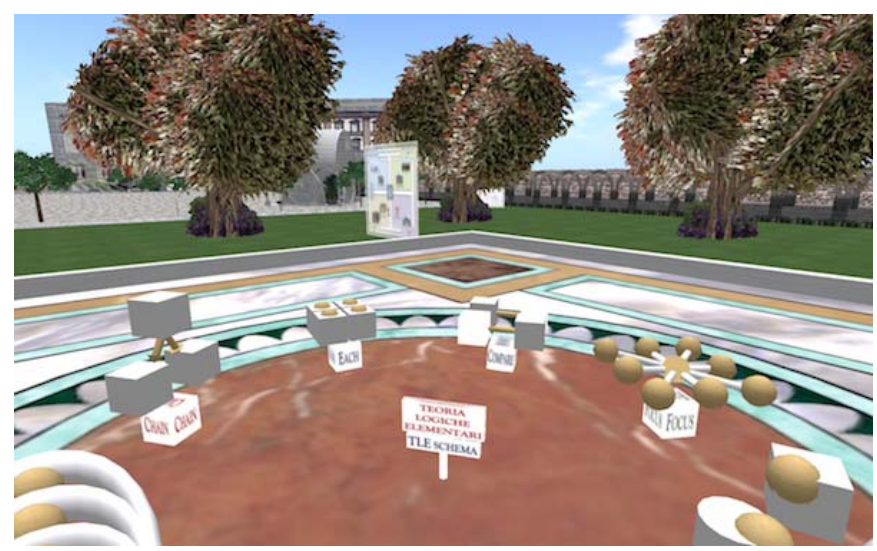

Fig. 2

in Federico 3DSU. Since it is a phylogenetic resource (Reber, 1989, 1992, 1993), implicit may operate as a default level underlying all cognitive activity and available on demand in relation to environmental experience. While explicit knowledge is increasingly complex, implicit knowledge is instead a type of unaware prototypal processing (Santoianni, 2011, 2016c), which may have simple models of expression and may influence both spatial conceptual reasoning (Santoianni, 2016a) and spatial guidance (Santoianni, 2016b), so facilitating spatial navigation.

To encourage adaptive navigation, an adaptive design should take into consideration the idea to give to the user the illusion to be in an everyday environment, where network services are available in intuitive ways (Bouras, Konidaris, Sevasti, Watson et al., 2000). The visuo-spatial organization of objects, if held constant in an environment design, may indeed influence the memory of its characteristics and may guide visual attention because of the "contextual cueing" effect (Chun, Jiang, 1998), which is related to the implicit organization of information content. In Federico 3DSU design, buildings are regularly placed according to focus Elementary Logic model and clickable objects are intuitively 


\section{Learning Environments}

Santoianni, Ciasullo

placed and shaped as everyday objects, available for daily use. In the welcome area, e.g., in the waiting room there are tables with books and journals placed on it (Fig. 3).

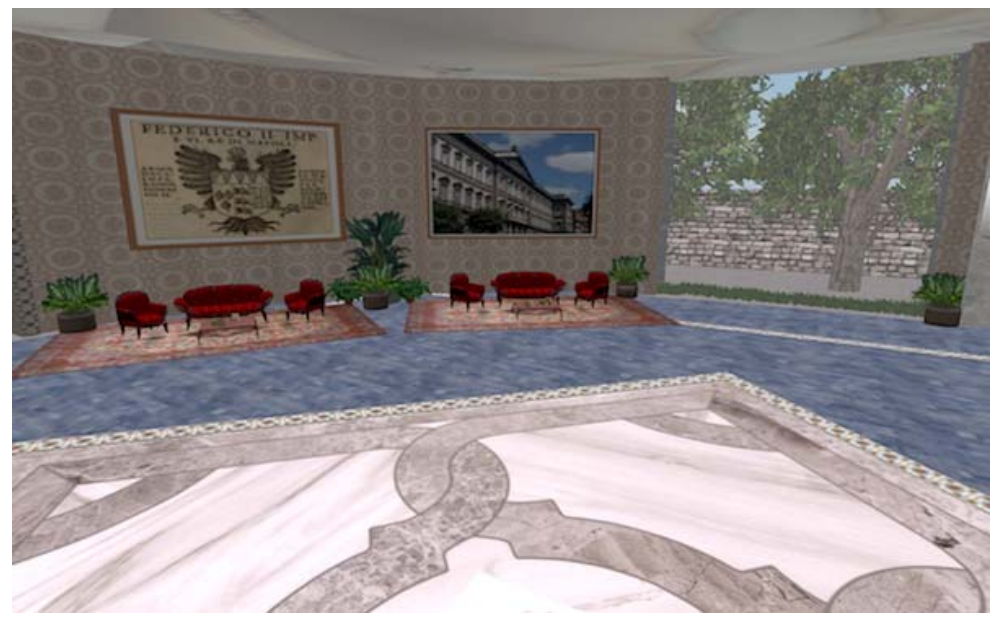

Fig. 3

If the user clicks on them, s/he will be redirected to the University web site in which open access research books and journals are freely available.

Virtual reality has three core principles - immersion, interaction, and user involvement - which are fully met in Federico 3DSU because, even if its accessibility is allowed as a usual computer-based desktop environment, which can be accessed by a conventional workstation, it gives anyway to learners the perception of being effectively physically present in a non-physical world (Freina, Ott, 2015). The concept of immersion means to feel a lack of awareness of time and of the real world (Jennett, Cox, Cairns, Dhoparee, Epps, Tijs, Walton, 2008), which can be reached by motivating and engaging users. An effective learning environment should indeed provide intensive interaction and feedback by having specific goals/tasks and providing the appropriate tools and procedures that fit them.

The Department of Humanities of the University of Naples Federico II is not faithfully reproduced in Federico 3DSU design to let high school and University students free to pursue her/himself personal learning pathway between the available welcome pathways to be guided into the University world. It has a formally regulated but still open structure divided in four main areas: Welcome Area, Adaptive Teaching and Learning Area, Digital Humanities Project Area, and Campus Meeting Area (Fig. 4).

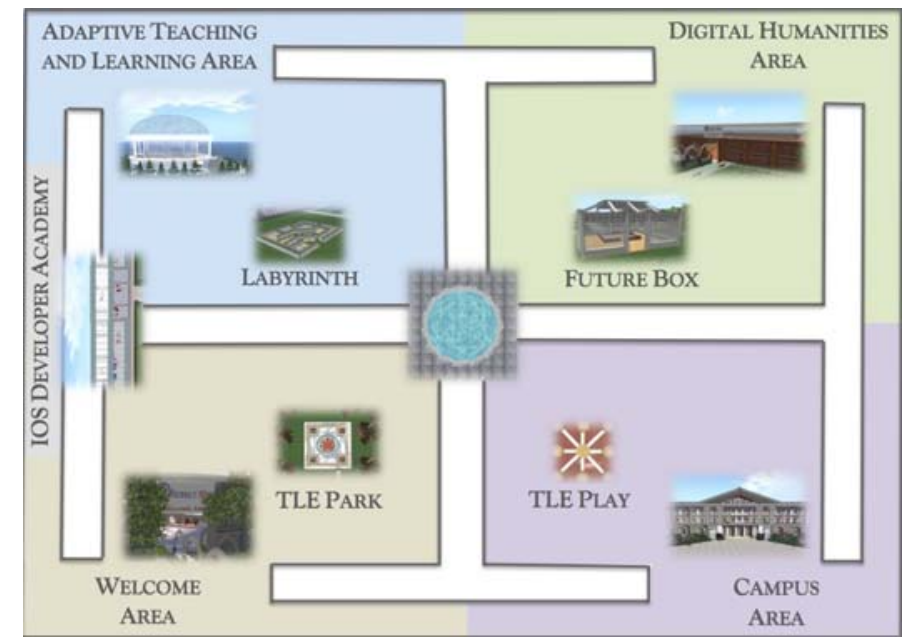

Fig. 4 


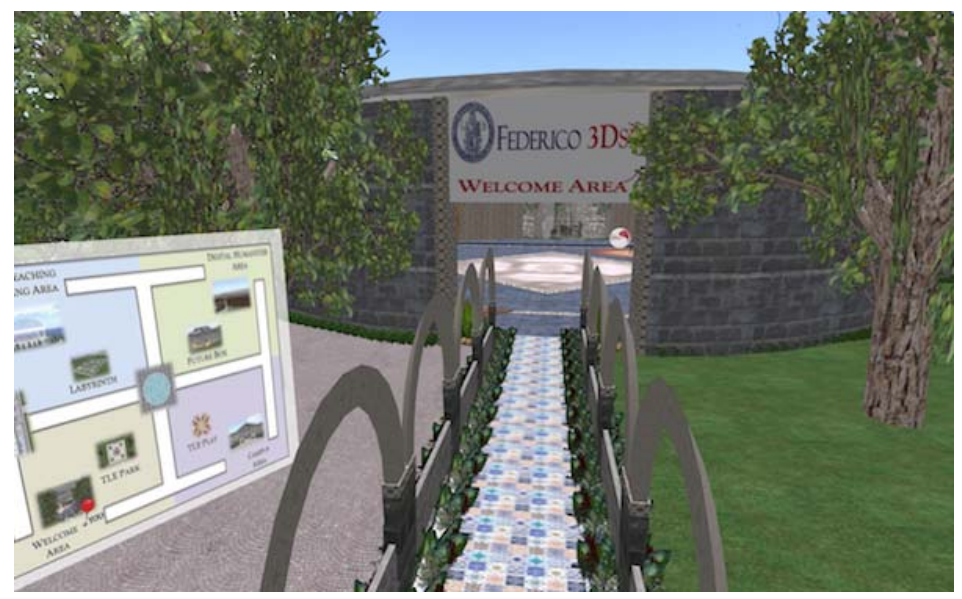

Fig. 5

The Welcome Area (Fig. 5) is designed to provide students with general information about the University of Naples Federico II - the history of the University, the present academic structure, and how to enroll - and, more in particular, to let them be updated about the Department of Humanities functionality and the available initiatives. Federico 3DSU collects and offers links to the internal resources of the various sections of the Department of Humanities, to show their activities and to facilitate students in participating to the University community life. The Welcome Area is related to both internal and external digital resources such as events, activities, projects, cultural websites, open access journals, MOOCs - in particular, the MOOCs of Federica.eu center and the open access journals of the SeReNa center of the University of Naples Federico II.

The Adaptive Teaching and Learning Area (Fig. 6)

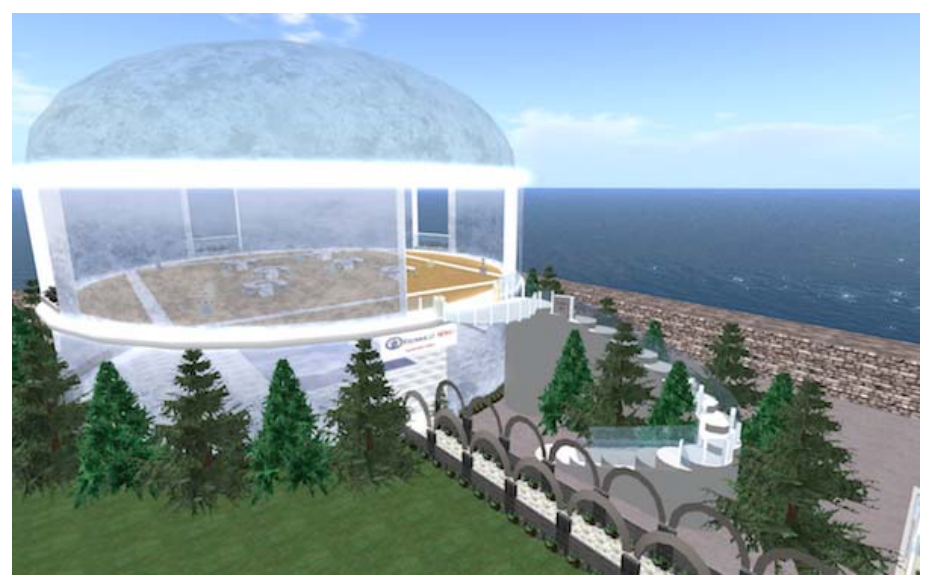

Fig. 6

is organized as a double level building in which - at first floor - students may gain appropriate cognitive tools to understand their own cognitive system. Here students are free to explore different areas of knowledge, linked to a near labyrinth in which learners may walk and discover information about cognitive functions. At second floor, pre-service and in-service teachers may search for applied research on educational theories and methodologies through the fruition of audios and videos to gain competencies about the main educational models, in order to meta-reflect on and to reformulate their own educational solutions.

Federico 3DSU is indeed a space for exploration of content and a meeting point for dialoguing groups, just opening digital accessibility to different responsive groups over the course of life, from youth (University and Secondary School students) to adulthood. Responsive groups are involved in cultural exchange, as cultural, social, and educational stakeholders (teachers and educators). The learning experience is designed for pre-service and in-service teachers, for researchers and professors from different disciplines, and for cultural, social, and educational professionals.

The Adaptive Teaching and Learning Area also involves the Apple Developer Academy of the Athenaeum, a partnership between the University of Napoli Federico II and Apple. Academy's program focuses on software development, startup creation and app design (Santoianni, Ciasullo, De Paolis, Nunziante, Romano, 2018) in an 


\section{Learning Environments}

Santoianni, Ciasullo

atmosphere of creativity and collaboration based on the innovative learning paradigm of Challenge Based Learning (Nichols, Cator, Torres, 2016) (Fig. 7).

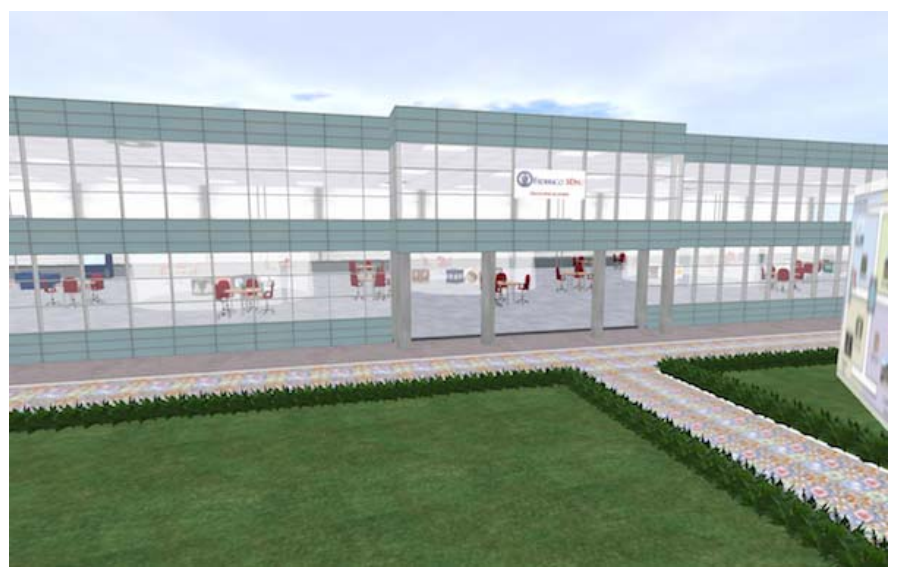

Fig. 7

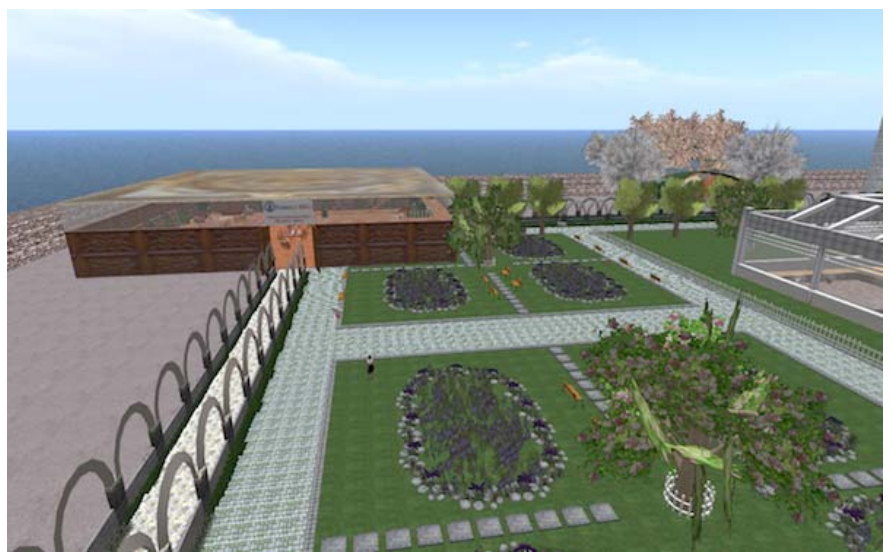

Fig. 8

The Digital Humanities Project Area (Fig. 8) has been designed to outline students what kind of field digital humanities are. Federico 3DSU introduces indeed digital humanities to learners showing them research projects in the field. Digital technologies offer new opportunities to study concepts, cultural artifacts, and their representations using virtual environments that allow the revisiting of places and events, and the experience of engaging learning experiences, through interactive interfaces. The experience of learning in immersive environments allow students to broaden their perspectives and future ideas for research development in digital humanities field and inform them about all the possibilities of study in the field of Digital Humanities, so playing an adaptive role in letting them understand their future job opportunities.

The Campus Meeting Area (Fig. 9)

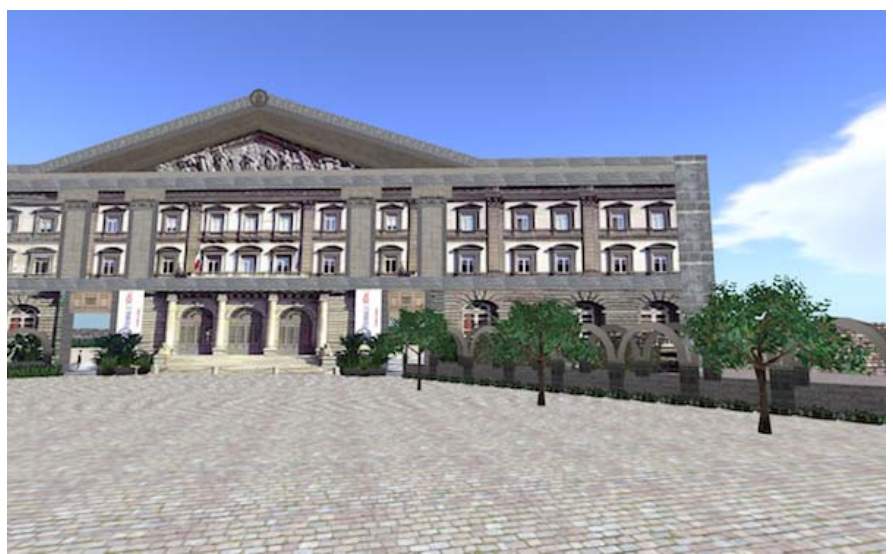

Fig. 9 
is rooted on the idea that $3 \mathrm{D}$ virtual learning environments for education are collaborative learning ecosystems which may represent a chance for personal growth and educational skills management of learners, in particular for new generations - who spend a considerable amount of their active lives in the digital domain. This area is organized to allow students to take advantage of University online digital resources and to develop University learning community.

Bio-Educational design is adaptive because of its two main characteristics:

- to tailor and customize educational offer in a dynamic continuous relation with learners, according to their own personal history of learning;

- to enhance the intertwining between the cognitive, emotional, and perceptual-bodily-organismic entanglement.

Learning shapes knowledge structures development in an adaptive way. Adaptive environments are learner centered and sensitive to educability criteria (Santoianni, 2006); they are indeed evolving contexts, where the developmental change is considered a key aspect of the educational process. For this reason, adaptive environments continuously modify their educational offer according to learning needs (Howard, Remenyi, San Juan, 2006). Federico 3DSU sustains personalized learning. The basic idea is the creation of an individual learning environment, adaptable to the specific needs of each student (Bopp, Hinn, Hampel, 2006). Users are left free to choose their own on demand learning evolutionary pathways and to discover educational opportunities and organization of concepts, accordingly to flexible monitoring of students and teachers' guidance actions. This aspect, which could be shared by other 3D virtual learning environments, here is differently treated. The freedom to explore the virtual environment is not lacking architectural boundaries, just because implicit scaffolding is needed to provide guidance to users at any moment, and in any place, they may need. Help/information is at users' disposal every time it is requested by a click on an object. Another chance - now in progress - is to give constant provision of help in a linked browser frame (Bouras, Konidaris, Sevasti, Watson et al., 2000). Federico 3DSU design is organized to sustain structural coupling ${ }^{1}$, i.e. in the Future Box students have the chance to change virtual environment's visual features through personalized spatial movements in a dedicated area, according to their future life choices, so allowing students to participate to their educational design (Fig. 10).

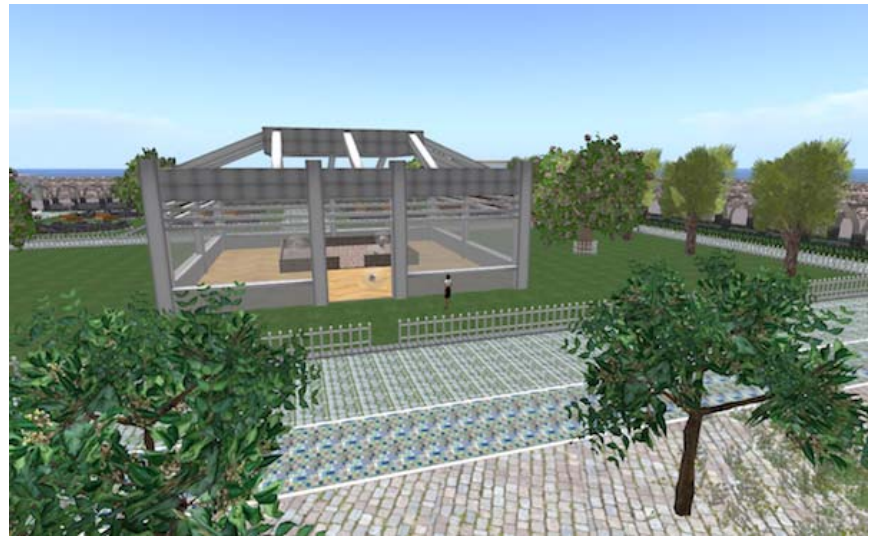

Fig. 10

Moreover, Federico 3DSU supports users to deepen their own cognitive identity through a walk in a labyrinth, where students may find on demand information about cognitive systems (Fig. 11).

\footnotetext{
${ }^{1}$ Structural coupling (Riegler 2002) is the word to mean a relationship in which the user can express her/his own conditions of environment's reset by requesting it to modify itself, while accepting the challenge of personal change.
} 


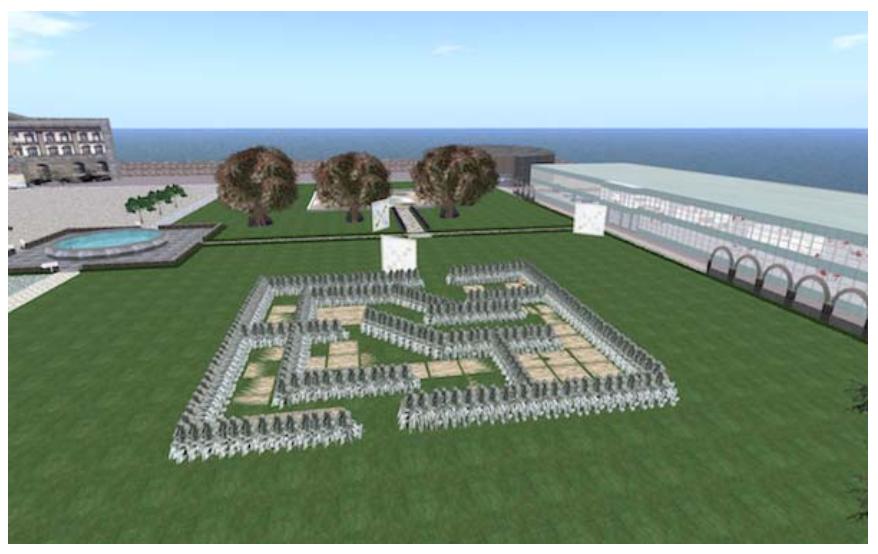

Fig. 11

Even if cognitive flexibility (Barak, Levenberg, 2016) is a basic competence of nowadays, a constant educational problem is students' disorientation. In a 3D Virtual Learning Environment, this problem may arise if there is a lack of guidance and support for students. Scaffolding is needed and may be activated before students start using the computers and during VLE fruition, in relation to content structure design (Nonis, 2005). If learning is to be considered an adaptive process, the role of teachers has to be re-thought accordingly (Santoianni, 2007). Teachers should be within the learning situation adopting evolving criteria of evaluation and situated views of learners' adaptive development, which requires a constant monitoring of learners' changing needs in order to continuously modify the learning environment itself.

Given the unpredictability of any teaching and learning situation, learning environments should be designed in evolutionary relation to learners' features. These can be afforded through an analysis methodology which concerns the cognitive, emotional, and perceptual bodily-organismic dimension of learning. The adaptive perspective of bioeducational design implies indeed multimodal audiovisual experiences and both explicit and implicit activation.

Transforming symbolic data into sensory form and physically immerging users into a virtual simulation world may significantly influence learning and its re-shaping as an adaptive process. The theoretical framework of adaptive learning environments may be intertwined with the innovative potential of experimental bio-educational models (Santoianni, 2010) to enhance knowledge structures development. Federico 3DSU joins then the innovation potential of experimental models of bio-education with the new technologies of $3 \mathrm{D}$ modeling in web environments. Its research potential is going to be tested in a small-scale environment.

\section{References}

Barak, M., Levenberg, A. (2016). Flexible Thinking in Learning: Individual Differences Measure for Learning in Technology-Enhanced Environments. Computers \& Education 99: 39-52.

Belingard, L., Péruch, P. (2000). Mental Representation and the Spatial Structure of Virtual Environments. Environment and Behavior 32(3): 427-442.

Bopp, T., Hinn, R., Hampel, T. (2006). A Service-Oriented Infrastructure for Collaborative Learning in Virtual Knowledge Spaces. In D. Kumar, J. Turner (Eds.), Education for the $21^{\text {st }}$ Century-Impact of ICT and Digital Resources (35-44). Boston: Springer.

Bouras, C., Konidaris, A., Sevasti, A. (2000). Virtual Environments in Educational Networks. In D.M. Watson et al. (Eds.), Communications and Networking in Education (195-203). Laxenburg: International Federation for Information Processing.

Brusilovsky, P. (2001). Adaptive Hypermedia. User Modeling and User Adapted Interaction 11(1/2): 87-110.

Brusilovsky, P. (2003). Adaptive Navigation Support in Educational Hypermedia: the Role of Student Knowledge Level and the Case for Meta-Adaptation. British Journal of Educational Technology 34(4): 487-497.

Buzan, B., Buzan, T. (2000). The Mind Map Book. London: BBC Books.

Chen, S.Y., Paul, R.J. (2003). Individual Differences in Web-Based Instruction. An Overview. British Journal of Educational Technology, 34(4): 385-392. 


\section{Adaptive Design for Educational Hypermedia Environments and Bio-Educational Adaptive Design for 3D Virtual Learning Environments \\ Santoianni, Ciasullo}

Chun, M., Jiang, Y. (1998). Contextual Cueing: Implicit Learning and Memory of Visual Context Guides Spatial Attention. Cognitive Psychology 36: 28-71.

Ciasullo, A. (2015). Armonie bioeducative. Milano: FrancoAngeli.

Dunn, R., Dunn, K. (1978). Teaching Students through their Individual Learning Styles. Reston: Reston Publishing. Fischer, B.B., Fischer, L. (1979). Styles in Teaching and Learning. Educational Leadership 36: 245-254.

Fischer, K.W., Daniel, D.B., Immordino-Yang, M.H., Stern, E., Battro, A., Koizumi, H. (2007). Why Mind, Brain, and Education? Why Now? Mind, Brain, and Education 1(1): 1-2.

Fischer, K.W., Goswami U., Geake J. (2010). The Future of Educational Neuroscience. Mind, Brain, and Education 4(2): 68-80.

Frauenfelder, E., Santoianni, F. (Eds). (2003). Mind, Learning and Knowledge in Educational Contexts. Cambridge: Cambridge Scholars Press.

Frauenfelder, E., Santoianni, F., Ciasullo A. (2018). Implicito bioeducativo. Emozioni e cognizione. RELAdEI Neuroscienze e problematiche educative, in press.

Freina, L., Ott, M. (2015). A Literature Review on Immersive Virtual Reality in Education: State of the Art and Perspectives. The 11th International Scientific Conference eLearning and Software for Education Bucharest April, 133141.

Honey, P., Mumford, A. (1986). The Manual of Learning Styles. Maidenhead: Peter Honey.

Howard, L., Remenyi, Z., San Juan, G.P. (2006). Adaptive Blended Learning Environments. 9th International Conference on Engineering Education T3K-16 July.

Jennett, C., Cox, A.L., Cairns, P., Dhoparee, S., Epps, A., Tijs, T., and Walton, A., (2008). Measuring and defining the experience of immersion in games. International journal of human-computer studies 66 (9): 641-661.

Kolb, D.A. (1978). Learning Style Inventory Technical Manual. Boston: McBer \& Co.

Kolb, D.A. (1984). Experiential Learning. Prentice Hall: Englewood Cliffs.

Magoulas, G.D., Papanikolaou, K., Grigoriadou, M. (2003). Adaptive Web-Based Learning: Accommodating Individual Differences through System's Adaptation. British Journal of Educational Technology 34 (4): 511-527.

Nichols, M., Cator, K., Torres, M. (2016). Challenge Based Learner User Guide. Redwood City: Digital Promise.

Nonis, D. (2005). 3D Virtual Learning Environments (3D VLE). Singapore: Educational Technology Division, Ministry of Education.

Novak, J.D. (1998). Learning, Creating, and Using Knowledge: Concept Maps as Facilitative Tools for Schools and Corporations. Mahwah: Lawrence Erlbaum.

Novak, J.D., Gowin, B. (1984). Learning How to Learn. Cambridge: Cambridge University Press.

Papanikolaou, K.A., Grigoriadou, M. (2004). Accommodating Learning Style Characteristics in Adaptive

Educational Hypermedia. In G. Magoulas, S. Chen (Eds.), Proceedings of the Workshop on Individual Differences in Adaptive Hypermedia in AH2004, Part I (77-86). Nederlands: Eidhoven.

Paramythis, A., Loidl-Reisinger, S. (2004). Adaptive Learning Environments and e-Learning Standards. EJEL

Electronic Journal of e-Learning 2(2): 181-194.

Reber A.S. (1989). Implicit Learning and Tacit Knowledge. Journal of Experimental Psychology: General 118(3): 219-235.

Reber A.S. (1992). The Cognitive Unconscious: An Evolutionary Perspective. Consciousness and Cognition 1: 93113.

Reber, A.S. (1993). Implicit Learning and Tacit Knowledge. An Essay on the Cognitive Unconscious. Oxford: Oxford University Press.

Riegler, A. (2002). When is a Cognitive System Embodied? Cognitive Systems Research 3(3): 339-348.

Sadler-Smith, E., Smith, P.J. (2004). Strategies for Accommodating Individuals' Styles and Preferences in Flexible

Learning Programmes. British Journal of Educational Technology 35(4): 395-412.

Santoianni, F. (2000). Dov'è la mente. In F. Santoianni, M. Striano, Immagini e teorie della mente (113-124). Roma:

Carocci.

Santoianni, F. (2004). La ricerca nelle scienze bioeducative. In E. Frauenfelder, F. Santoianni \& M. Striano, Introduzione alle scienze bioeducative (33-70). Roma-Bari: Laterza.

Santoianni, F. (2006). Educabilità cognitiva. Apprendere al singolare, insegnare al plurale. Roma: Carocci.

Santoianni, F. (2007). Bioeducational Perspectives on Adaptive Learning Environments. In F. Santoianni, C.

Sabatano (Eds.), Brain Development in Learning Environments. Embodied and Perceptual Advancements (83-96).

Cambridge: Cambridge Scholars Publishing.

Santoianni, F. (2010). Modelli e strumenti di insegnamento. Roma: Carocci.

Santoianni, F. (2011). Educational Models of Knowledge Prototypes Development. Mind \& Society, 10, $103-129$.

Santoianni, F. (2014). Modelli di studio. Apprendere con la teoria delle logiche elementari. Trento: Erickson.

Santoianni, F. (2016a). Spaces of Thinking. In F. Santoianni (Ed.), The Concept of Time in Early Twentieth-Century Philosophy. A Philosophical Thematic Atlas (5-14). Switzerland: Springer International Publishing. 


\section{Learning Environments}

Santoianni, Ciasullo

Santoianni, F. (2016b). Phenomenology and Perception of Time Maps. Language and Thinking of Time Maps. Science and Logic of Time Maps. In F. Santoianni (Ed.), The Concept of Time in Early Twentieth-Century Philosophy. A Philosophical Thematic Atlas (35-38; 126-128; 199-202). Switzerland: Springer International Publishing.

Santoianni, F. (2016c). Formación Implícita de las Estructuras del Conocimiento. Modelos Elementales de Interacción y Funciones del Cambio. In A. Scocozza, G. D’Angelo (Eds.), Magister et Discipuli: Filosofía, Historia, Política y Cultura 2 (423-434). Bogotá: Penguin Random House.

Santoianni, F. (2017). Models in Pedagogy and Education. In L. Magnani, T. Bertolotti (Eds.), Springer Handbook of Model-Based Science (1033-1049). Cham (ZG), Switzerland: Springer International Publishing.

Santoianni, F. (2018). Teorie emergenti in campo bioeducativo. RTH Research Trends in Humanities 5: 12-21.

Santoianni, F., Ciasullo, A. (2017). Bios, Logos, and Soft Skills for Contemporary Education. Philosophy of Education 1(10): 179-188.

Santoianni, F., Ciasullo, A., De Paolis, F., Nunziante, P., Romano S.P. (2018). Federico 3DSU. Adaptive Educational Criteria for a Multi-User Virtual Learning Environment. Journal of Virtual Studies. Special Proceedings of the Immersive Learning Education Conference 9(1): 9-16.

Santoianni, F., Osorio Guzmàn, M. (2015). Inside the Cognitive Prism. Possible Correlations between Explicit Intelligences and Implicit Knowledge Prototypes. Exploring Cognitive Variability in University Students of Philosophy. Philosophy of Education 8: 1811-0916.

Schwartz, M. (2015). Mind, Brain and Education: A Decade of Evolution. Mind, Brain, and Education 9(2): 64-71.

Sternberg, R.J. (1997). Le tre intelligenze. Trento: Erickson.

Sternberg, R.J. (1998). Stili di pensiero. Trento: Erickson.

Sternberg, R.J., Grigorenko, E. (2001). A Capsule History of Theory and Research on Styles. In R.J. Sternberg, L.F. Zhang (Eds.), Perspectives on Thinking, Learning, and Cognitive Styles (1-21). Mahwah: Lawrence Erlbaum.

Sternberg, R.J., Grigorenko, E.L. (1997). Are Cognitive Styles still in Style? American Psychologist 52: 700-712.

Sternberg, R.J., Zhang, L.F. (2001). Perspectives on Thinking, Learning, and Cognitive Styles. Mahwah: Lawrence Erlbaum.

Wallach, M., Kogan, N. (1965). Modes of Thinking in Young Children. New York: Holt, Rinehart \& Winston.

Wang, M.C. et al. (1984). Report. The Adaptive Learning Environments Model: Design, Implementation, and Effects. Washington: National Institute of Education.

Wolf, C. (2002). iWeaver: Towards an Interactive Web-Based Adaptive Learning Environment to Address Individual Learning Styles. Interactive Computer Aided Learning Workshop (ICL2002) Villach Austria.

Zhang, L.F., Sternberg, R.J. (2005). A Threefold Model of Intellectual Styles. Educational Psychology Review 17(1): 1-53.

Zhang, L.F., Sternberg, R.J. (2006). The Nature of Intellectual Styles. Mahwah: Lawrence Erlbaum. 